\title{
POLOS DE APOIO PRESENCIAL: entraves em sua manutenção
}

\author{
Luciana Souza Santos Silveira \\ Trabalho Final de Curso (TFC) \\ Estudante do curso de Pós-Graduação (Final de curso), UFF, Rio de Janeiro-RJ \\ lucisouza2703@gmail.com
}

\begin{abstract}
RESUMO
A Educação à Distância tem no seu acesso a possibilidade de diminuir a distância entre educando e o conhecimento. E os polos de apoio presencial fazem esta ponte para dar suporte a quem se encontra distante de sua Instituição de Ensino. Este trabalho tem como objetivo compreender a implementação e manutenção de polos de apoio presencias de educação à distância. O presente trabalho descreve as etapas que englobam essa implementação e aponta as dificuldades encontradas na manutenção destes polos. Usamos pesquisas já feitas por outros autores para análise e reflexão deste estudo. Por meio do desenvolvimento do presente trabalho, foi possível observar que a educação à distância apesar de estar caminhando a passos largos, ainda faltam algumas estratégias a serem desenvolvidas, principalmente referente às políticas públicas para facilitar o andamento e manutenção dos polos de apoio presencial.
\end{abstract}

Palavras-chave: (Educação à Distância, Implementação, Polo de Apoio Presencial).

\section{INTRODUÇÃO}

A evolução das tecnologias da informação tem proporcionando muitas mudanças sociais, culturais e econômicas. E esta crescente disponibilização de informações tem como consequência a facilidade do acesso ao conhecimento.

A Educação à distância surge então favorecida pela mediação das novas tecnologias, facilitando e diminuindo a distância entre educando e educador.

No mundo, a história da Educação à distância é antiga, segundo Alves (2011), e iniciou no século XVIII. Já no Brasil, segundo Alves (2011) os primeiros registros se dão no século XX. Na década de 90 surgiram no Brasil as primeiras ferramentas de apoio virtual para aprendizagem, surgindo assim a EAD on-line. Mas somente em 1996 foi criada a Secretaria de Educação a Distância (SEED). E também neste mesmo ano foi estabelecido a Lei de Diretrizes de Bases da Educação Nacional no 9.394, de 20 de dezembro de 1996, artigo 80, "O Poder Público incentivará o desenvolvimento e a vinculação de programas de ensino a distância, em todos os níveis e modalidades de ensino, e de educação continuada" - (Brasil, 1996) dando início oficial a Educação à Distância no Brasil. Embora tenha sido regulamentada somente em 2005 pelo Decreto no 5.622 (BRASIL, 2005). E em 2005 foi criada a Universidade Aberta do Brasil. 
Neste cenário de acelerado crescimento e evolução da modalidade de Educação à Distância consideramos o estudo sobre implementação e a gestão de polos presenciais de grande importância para o sucesso e a manutenção destes polos, onde se tem a possibilidade de disseminação da educação em lugares ou para pessoas que até então não tinham acesso a esta educação que é direto de todos. Observamos que são poucos os textos neste campo de estudo.

Este vultuoso crescimento em tão pouco tempo se deu apesar da tentativa por parte do Governo Federal de incentivar a Educação à Distância que através do investimento privado tomou frente e dominou o cenário da EAD.

Mudando também o cenário da educação no Brasil, ajudando a ampliar as possibilidades de acesso ao ensino-aprendizagem.

Fazendo-se necessário profissionais competentes e qualificados para atuarem na gestão, implementação e manutenção de cursos a distância.

Na perspectiva de Levi (1993) citado por Pequeno (2004), ocorre a necessidade da geração de educando ou do profissional que está se instruindo uma compreensão mais definida sobre as ações e o papel da gestão de aprendizagem.

A proposta do trabalho foi analisar os mecanismos para a implementação dos cursos EAD abordando aspectos de planejamento, da gestão, físicos (polos presencias) e recursos humanos. Elencar os aspectos favoráveis e primordiais para a manutenção de cursos de excelência, atendendo à demanda crescente de discentes.

\section{METODOLOGIA}

O trabalho desenvolvido seguiu preceitos do estudo exploratório, por meio de uma pesquisa bibliográfica.

$\mathrm{Na}$ etapa da análise e interpretação dos dados foi feito um estudo mais minucioso e a análise do ponto de vista dos autores que atenderam a temática do referido trabalho $\mathrm{Na}$ fase da discussão dos resultados propusemos o cruzamento e análise das informações publicadas pelos autores estudados e a observação dos documentos oficiais produzidos por órgãos fomentadores do desenvolvimento da EAD no Brasil.

A metodologia foi utilizada para um melhor entendimento sobre as etapas que englobam o planejamento, implementação e manutenção dos polos presenciais dos cursos de educação à distância (EAD). Foi feita uma investigação por meio de uma ampla pesquisa bibliográfica com o objetivo de gerar conhecimento das etapas que melhor possam conduzir um planejamento e a implementação de um curso de EAD.

Este trabalho foi organizado em nove seções organizadas de maneira a facilitar o entendimento do leitor. Começando pela introdução que apresentou o assunto pesquisado de forma sucinta e objetiva e obtendo uma visão total do trabalho. $\mathrm{Na}$ etapa da justificativa foi exposto a importância do tema escolhido e o motivo da necessidade do estudo. Objetivo foi a sessão em que foi detalhado onde este estudo tem intenção de chegar, que serve como um norte para direcionamento da pesquisa. $\mathrm{Na}$ Metodologia foi definido o caminho, o método que se utilizou para se chegar ao resultado da pesquisa, determinando quais os autores que iram ser estudados. $O$ trecho "Pressupostos Teóricos" foi utilizado para que pudéssemos explicar o porquê da escolha do nosso estudo, e, com isso foi possível o desenvolvimento da arguição. Foram abordadas as ideias de vários autores essenciais nas questões levantadas 
nesta pesquisa. Na parte dos resultados e discussões foram feitas as análises e reflexões argumentativas dos autores escolhidos para o referido estudo e também um quadro comparativo com as principais ideias dos autores. Para a Conclusão foi feita uma análise e reflexão dos objetivos alcançados com a pesquisa. Já nas referências bibliográficas foi exposta todas as publicações utilizadas para o estudo do referido trabalho.

\section{Resultados e Discussões}

O planejamento influencia diretamente a eficiência na gestão e administração de um projeto. A preparação, organização e estruturação dos objetivos auxilia na tomada de decisões e execução de cada tarefa do planejamento.

Um projeto pedagógico institucional bem definido compatível com o público-alvo é o alicerce para o sucesso de um planejamento de curso à distância de qualidade.

O planejamento de um curso de EAD deve ser minucioso em todas as etapas do desenvolvimento, seja na concepção, produção ou implementação dos cursos. É preciso estar bem definido os objetivos que se quer atingir e condizente com a visão da instituição.

Durante o processo de montagem do planejamento podemos observar a existência de fases que constituem a elaboração de um curso, seja ele EAD (Ensino à Distância) ou presencial.

Analisadas as fases envolvidas no processo de construção do planejamento notamos que em comum elas possuem como objetivo central o aluno e que o papel do gestor é conduzir suas equipes afim de que estas executem suas atividades de maneira dinâmica e integrada.

A etapa de implementação do curso é a execução do planejamento do curso, levando em consideração as determinações do processo de ensino e aprendizagem, bem como requisitos técnicos e tecnológicos para seu desenvolvimento.

Observamos que esta é a fase em que ocorre a implantação da estrutura tecnológica com o intuito de consolidar e ampliar a estrutura pedagógica colocando em prática as ações educacionais propostas no PPI.

Para o sucesso da implantação e do acompanhamento do programa de ensino à distância encontramos no documento publicado pelo MEC titulado "Referenciais de Qualidade", datado de 02 de abril de 2003 o qual aborda quesitos de qualidade para a implantação de cursos EAD.

Mesmo com estes "Referenciais de Qualidade", os polos presencias passam por graves problemas.

No polo de apoio presencial compartilham o mesmo espaço físico o MEC/UAB, IES e o mantenedor do polo, seja o Município ou o Governo do Estado, tendo a possibilidade possuir cursos com características diferentes, portando o gerenciamento de um polo é muito complexo por se tratar de uma diversidade de objetivos, de recursos envolvidos e colaboradores. Estes polos são criados para serem um ponto de apoio para estudantes e instituições onde são oferecidos os cursos. Tornando assim possível a regionalização da oferta da educação e sua expansão.

Segundo (Ribas, Moreira, Catapan, 2011) os polos nem sempre conseguem cumprir estes requisitos, visto que o Governo Federal atrasa ou deixa de enviar os recursos, dificultando a gestão e operacionalização destes polos.

Outros problemas que são enfrentados segundo Bastos, et.al (2013) é o acesso à internet que em muitos lugares do interior do País é deficitário, dificultando assim o ensino-aprendizagem. $\mathrm{E}$ a dificuldade em conseguir profissionais qualificados, para integrar uma equipe que precisa ser multidisciplinar. 
Outra peculiaridade que se encontra nas unidades operacionais é encontrar diferentes projetos pedagógicos em um mesmo local, e com isto a frequência de seus colaboradores podem variar de curso para curso, requerendo acompanhamento e supervisão do coordenador do polo.

Com todos estes desafios a serem enfrentados o polo necessita de um gestor que tenha comprometimento com o ensino aprendizado.

\section{Conclusões}

Apesar da Educação à Distância ter tido um grande avanço principalmente com o surgimento das novas tecnologias, ainda há muito o que se fazer para que realmente essa educação seja uma educação à distância e não uma educação distante.

A Educação à Distância tem o mesmo objetivo da Educação Presencial que é a de transmitir conhecimento, mas com peculiaridades, principalmente quando falamos sobre os polos de apoio presencial. Um exemplo disto é na necessidade de regulamentar o regime de colaboração entre os entes federados, permitindo maior clareza para a participação efetiva dos federados.

A maioria dos problemas encontrados na implementação e manutenção do polo de apoio presencial passa pelo viés da política pública. Se faltam políticas públicas adequadas, acontecem os entraves durante todo o processo de gestão.

Pode-se concluir que para a EAD o aluno é a parte principal desde o início do projeto, que é agente de seu desenvolvimento. E para isso a necessidade de promover uma educação de qualidade. Todas as etapas que envolvem a implantação e construção de um curso requer uma equipe multidisciplinar com gestores envolvidos e conscientes de seu papel dentro do processo de ensino-aprendizagem.

\section{Referências}

ALVES, Lucineia. Educação à distância: conceitos e história no Brasil e no mundo. Rbaad - Educação à Distância: Conceitos e História no Brasil e no Mundo, Rio de Janeiro, v. 10, p.83-92, 2011. Disponível em: < http://www.abed.org.br/revistacientifica/Revista_PDF_Doc/2011/Artigo_07.pdf />. Acesso em $27 \mathrm{Fev}$. de 2015.

BASTOS, Adriana Teixeira et al. Polos de apoio presencial: requisitos e desafios da gestão. In: ESUD - Congresso brasileiro de ensino superior à distância, 10, 2013, Belém/pa. Artigo. Belém: Unirede, 2013. p. 1 - 12. Disponível em:< http://www.aedi.ufpa.br/esud/trabalhos/poster/AT1/114304.pdf> Acesso em: 01 jun. 2015.

CHAVES, Anísia; BARROS, Moisés Pereira de; SILVA, Marcelo Leocádio Rocha. Projeto de Implantação da educação à distância na UTRAMIG - FASE II Coordenação: Profa. Ms. Rosângela Maluf Equipe: Anísia Chaves Moisés Pereira de Barros Marcelo Leocádio Rocha Silva Belo Horizonte Maio. 2012. Disponível em: <http://www.administradores.com.br/producao-academica/projeto-para-implantacaodo-ensino-a-distancia-na-utramig/5078/download/>. Acesso em: 28 fev. 2015.

FISCARLLI, Rosilene Batista de Oliveira. Material didático: discursos e saberesJunqueira \&Marin: Araraquara, SP,2008

KENSKI, Vani. Tecnologias e Ensino Presencial e a Distância. Campinas, SP: Papirus, 2003 157p. (Série Prática Pedagógica).

PAULA, Keilla Carrijo de; FERNEDA, Edilson; CAMPOS FILHO, Maurício Prates de. Elementos para implantação de cursos à distância. 2004. Disponível em: <http://ricesu.com.br/colabora/n7/artigos/n_7/pdf/id_02.pdf>. Acesso em: 27 fev. 2015. 